\title{
THE FUNDAMENTALS OF AN EARTHQUAKE STANDARD
}

\author{
A. B. King'
}

\begin{abstract}
This paper proposes a rational framework for an earthquake design standard which could be adopted and applied internationally. Initially the standard is expected to be used within New Zealand and Australia as one component within a suite of joint structural standards which would enable design and construction practices to be applied either side of the Tasman. The framework could be easily adopted by other countries because it addresses both inter- and intra- plate earthquakes. Allowance is made for national variations to address varying levels of seismicity and different national performance expectations. The author outlines his views on the objectives and expected contents of the essential elements of an earthquake loading standard which are currently being examined in detail by a Standards Australia and Standards New Zealand working party.
\end{abstract}

\section{INTRODUCTION}

Over recent years, since the New Zealand economic revival, New Zealand industry has accepted the challenge of international trade across all sectors of our economy. Nowhere more so than in the building industry where building products, design and construction technology, and New Zealand technical expertise are being applied within Australia, Asia and the Pacific Rim. Advances in telecommunication and computer technology make New Zealand less isolated and more able to participate, and favourably influence, development of sound building control codes and standards. This is occurring at a time when both the technical and financial resources required to develop new, or even maintain existing, structural design standards have become increasing difficult to obtain within New Zealand.

The logical solution to this dilemma is to be influentially involved in the development of common standards which can be used both within New Zealand and within the borders of our trading partners. It is important that this involvement is active to ensure that the high performance expectations contained within our existing structural design standards are not compromised.

Earthquakes dominate the structural design process within New Zealand. Consideration of both post-elastic, ductile response and capacity design principles are commonplace. This reflects New Zealand's moderate to high seismicity. This is in distinct contrast to structural design in Australia where most regions are of moderate to low seismicity and do not merit such considerations. While most Australian buildings provide lateral resistance for wind loads, post-elastic response and structural ductility are seldom specifically considered or provided.
Nowhere is New Zealand's technical expertise more widely acknowledged than in the area of earthquake engineering. This paper proposes a rational framework for an earthquake design standard which could be adopted and applied internationally. Initially, and in accordance with the New Zealand - Australia free trade agreement, the standard is expected to be used within New Zealand and Australia as one component within a suite of structural standards which would enable design and construction practices to be applied either side of the Tasman. The framework is sufficiently robust that it could be adopted by other countries because it provides for both inter- and intracontinental earthquakes. National variations would be required to account for varying levels of seismicity and different national performance expectations.

In this paper, the author outlines his views on the objectives and expected contents of the essential elements of an earthquake loading standard. Three major issues within the earthquake design process are identified and discussed in detail in the following sections. The first issue is the basis for determining the ground motion expected during an event with an appropriate recurrence interval (as required by each national building code) for each region within the coverage region of the standard. The second issue is the adjustments to the ground motion which are required for the structure to meet the performance expectations of the community. The third issue is the means of translating the adjusted ground motion into the dynamic response of the structure.

The elements described in this paper are currently being examined in detail by Standards Australia and Standards New Zealand working party BD6/4. It is expected that the conclusions of the working party will be presented in the Bulletin in the near future. 


\section{DEVELOPING A JOINT EARTHQUAKE DESIGN STANDARD.}

Many key issues need to be considered regardless of the level of seismicity present. By focusing specifically on New Zealand and Australian requirements, aspects have been identified which require national variations. These variations reflect differences in the performance expectations the two societies have of their building stock along with differences in construction and design practice and the reliability of the structures which result. Ideally, national variance factors would be provided as a means of attaining stated target safety indices under each load combination which needs to be considered. As such they may differ with different load cases and different load,ratios, but should be similar for constructions of different materials and structural forms.

A schematic representation of the earthquake design process is given in Figure 1. The items within this schematic are numbered in accordance with the subsequent sections of this paper. For reference, the key elements of each of these items are summarised in Appendix A for several international earthquake standards.

Each item in the following sections of this paper identifies its objective, (typeset in italics), discusses the issues involved (in normal text) and anticipates the outcome which may evolve from detailed considerations (in bold italics).

\section{PRESCRIPTION OF THE DESIGN EARTHQUAKE GROUND MOTION}

\{Objective: To prescribe the dynamic response characteristics of any site to earthquake ground motion such that the hazard resulting from that motion is uniform and has a probability of excedence consistent with that demanded by the national building code.\}

\subsection{Site Response}

\{Objective: To prescribe the dynamic response characteristics of rock sites anywhere within each seismologically unique region that the design standard is to cover.

Earthquake induced ground motion is usually codified either as a response spectra, being a plot of one parameter of motion (ie. displacement, velocity or acceleration) against the response period, or as a plot of actual motion against time. Response spectra are the most convenient form and acceleration response spectra the most common form for publication within earthquake design standards because lateral forces can be directly derived from acceleration by multiplying it by the seismic mass present. There is however, an increasing demand that the overall building performance be considered as the basis for design. Force based design procedures are not particularly suitable for establishing either the onset of damage nor other displacement related performance criteria. There is thus an increasing trend towards using displacement spectra as the basis for design. Thus it may be expected that in the future, both acceleration and displacement design spectra will be published within the earthquake design standard. It is also possible that a suitable time history record (or suite of records) will be published that represents the same ground motion which formed the basis of the design spectra. Any of the above methods of representing the site ground motion are legitimate, but any methods should be consistent and transparent between each method.
Priestley [1993] outlined a displacement design method which can be used as the basis of codified design. Figure 2 indicates the character of typical acceleration and displacement response spectra prepared in this manner.

Alternative approaches, either being developed or in current practice, include using a combination of acceleration and velocity spectra as the basis for design and for assessing seismic hazard. Canada uses this approach to determine their seismic hazard potential across the country from which the level of earthquake design is determined (refer section 5.1) as outlined by Heidebrecht [1995].

When developing a common earthquake design standard for both interplate (moderate to high seismicity) zones such as New Zealand, and intraplate (low to moderate seismicity) zones such as Australia, response spectra could be published for each seismologically similar region. The basis upon which each is developed should be common. The significance of the nominated return period used to normalise the intensity of the 'design event' will be of greater significance within zones of low seismicity where the ratio of design intensity to maximum credible ground motion may be in the range of 2 to 3 , (cf 1.5 to 2 for zones of high seismicity). Thus the design parameters may be highly sensitive to the return period nominated as the 'design intensity' within such zones, yet insensitive within areas of greater seismicity.

Building damage is also acknowledged as being a function of the duration of high intensity excitation. The large magnitude design event associated with zones of high seismicity, can be expected to generate high intensity shaking which will continue for between 20 to 45 seconds ( $\mathrm{cf} 5$ to 10 seconds duration for the design event within zone of low seismicity). This relates directly to the number of inelastic excursions (and thus accumulated damage) the building may be expected to experience. Thus the duration of intense ground motion is an important parameter when assessing building damage but is yet to be satisfactorily codified.

Markedly different ground motion attenuation relationships may be expected between New Zealand (with its highly disturbed rock strata of relatively low shear modulus and shear wave velocity) and Australia (where the rock strata is largely undisturbed and the shear wave velocity is relatively high). Such effects will need to be incorporated into the development of the uniform hazard spectra for each country if this approach is to be used. There is currently a dearth of data which may preclude the use of this approach in the short to medium term. A rational basis for deriving a design spectra for vertical response will also be required for both New Zealand and Australia to enable the dynamic response of horizontally spanning elements (cantilevers, floor span members etc.) to be assessed

[Anticipated Outcome: Within a future earthquake design standard, the nominal site ground motion is likely to include both an acceleration and a displacement design spectra for each seismological zone. The peak intensity of any such spectra will probably be based on a uniform risk approach where the intensity of ground shaking relates to an event with a return period of that nominated for the specific limit state under consideration.]

\subsection{Regional Seismicity (Seismic Zonation Maps)}

\{Objective: To prescribe the a suite of scaling constants by which the normalised design spectra can be related to expected ground motion within zones of differing seismicity.\} 


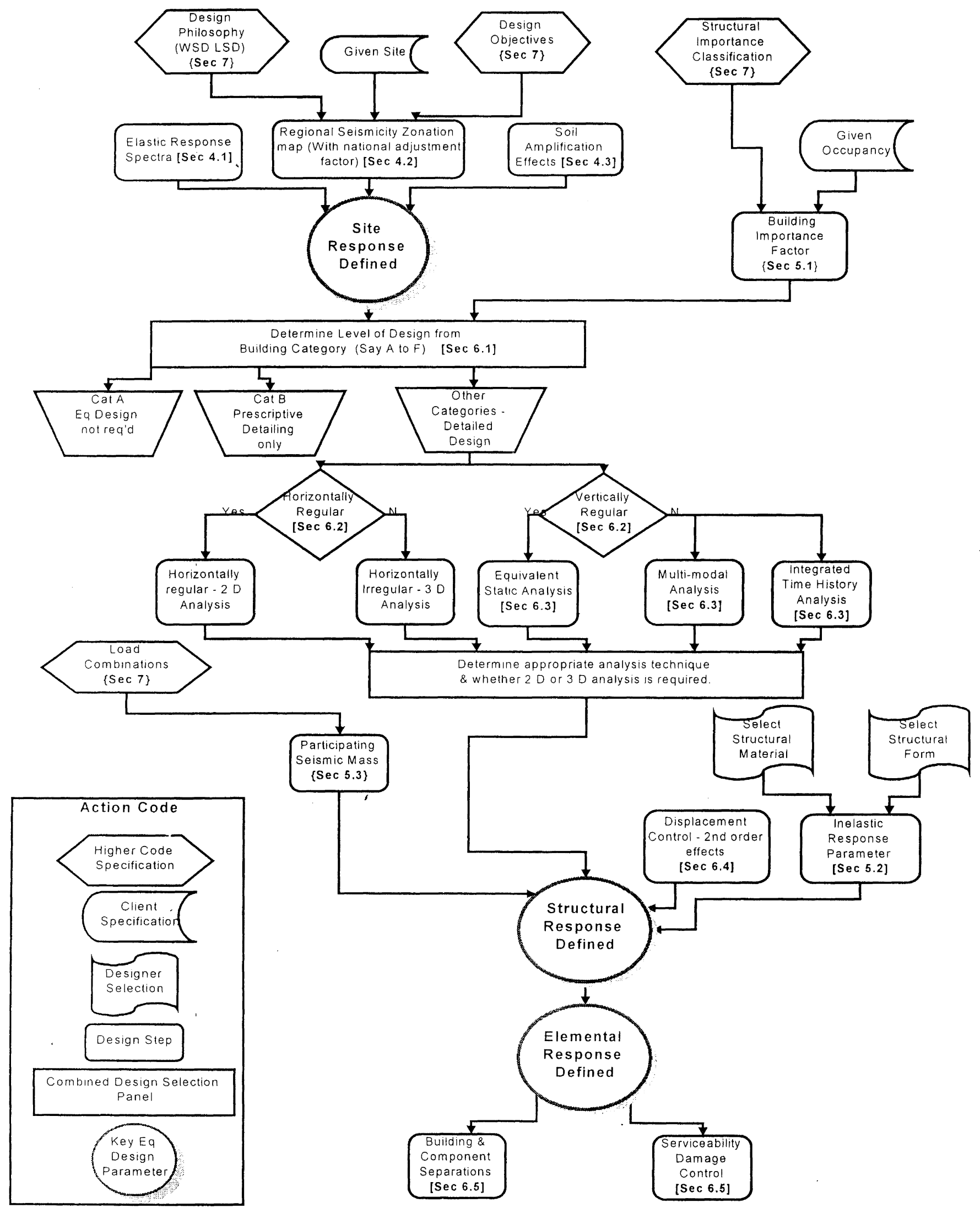



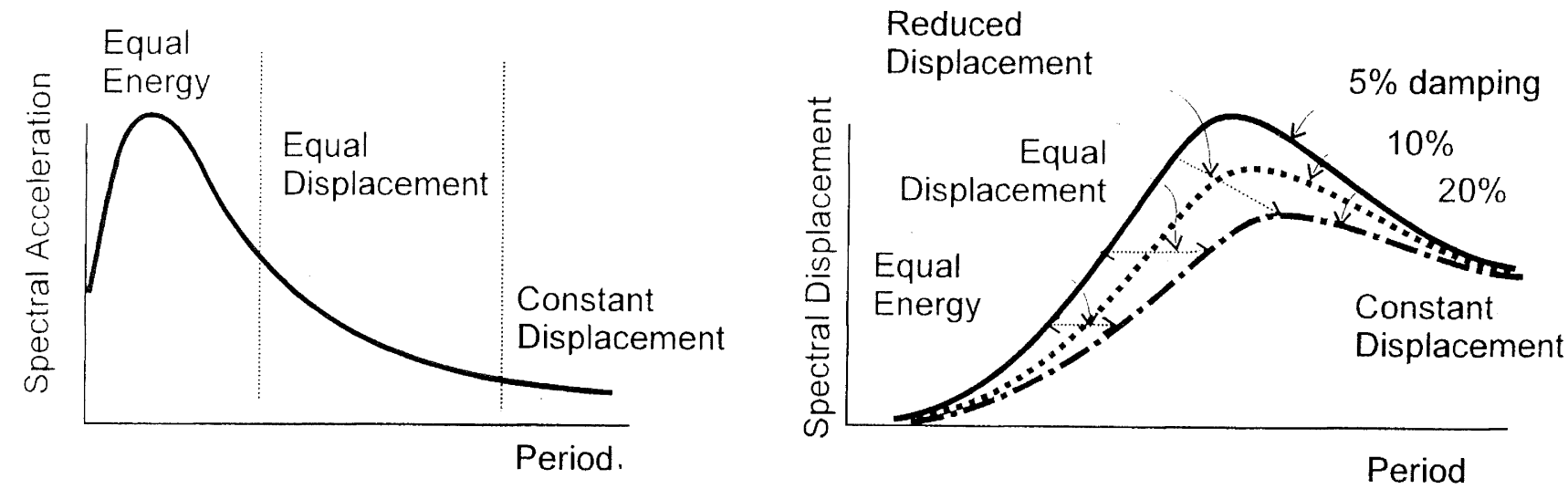

FIGURE 2 Typical Acceleration ans displacement response spectra (from Priestley [1993])

A method is required by which the nominal elastic response spectra prescribed in section 3.1 can be modified to reflect regional variations in seismicity. While it would be preferable to apply a single factor across the full period range, this may distort the design spectra and two or more period-related scale factors may be required. Modification factors may be presented as seismic zonation maps (which prescribe scale factors to various locations based on isoseismal style maps of each region). Alternatively one or more spectral ordinate maps may be used, with the resulting period dependant functions be used to adjust a generalised spectral shape.

[Anticipated Outcome: A suite of seismic zonation maps is expected. These will extend over all regions within coverage of the standard. They would need to be prepared on a common basis and be based upon a common recurrence interval. National risk adjustment factors may be introduced where the consumer expectation, as prescribed by the national building control system, requires a departure from the nominated recurrence interval of the design event.]

\subsection{Soil Amplification Effects}

\{Objective: To prescribe a method whereby the modifying influence of near-surface soil conditions on the nominal response can be ascertained.\}

The influence that near surface soil strata have in modifying the transmission of the energy waves released from the rupture plane must now be considered. Such effects are usually local to each site and are intended to reflect modifications which may occur to the energy shear waves released from the rupture surface as they pass through the surface layers. Such effects may either result in the amplification or attenuation of ground motion with factors of between 0.67 and 2.5 being typical.

Two common means of allowing for such effects are found within the mainstream overseas standards. A soil amplification factor is used in the UBC [ICBO, 1992] and Australia [Standards Australia, 1993] which has the effect of linearly scaling the normalised response spectra across the full period range. The alternative approach, adopted within the current New Zealand standard and the draft of European standard, assigns period dependant reference points that modify the overall spectra shape. This latter approach provides greater opportunity to realistically represent the actual site response.
Typically rock or stiff soil sites have greater short period response (ie greatest energy within the 0 to 0.4 second period range), but experience more rapid decay and lower long period response (refer Figure 3). Conversely, soft soils may filter (attenuate) some short period response, resonate and therefore amplify excitation when the basement excitation is sympathetic with their own natural period, and have little effect on longer period response. Thus a broad elevated response plateau should be expected about this natural period of the subsoils beneath a specific site. Unfortunately, within the broad parameters used to prescribe the site conditions, it is seldom practical to precisely identify this natural period of the site and therefore the period range whereby amplification can be expected. In such cases, an extended spectral plateau has been introduced to cover the amplification zone. This may often be narrowed with site specific evaluation.

In any regard, it is essential that the end-user (ie the structural engineer) is able to accurately determine which soil conditions should be applied to any given site. Thus, although shear wave velocity may be the actual site parameter which needs to be considered, a fuller description of geotechnical properties (such as depth, density, cohesion etc.) may be necessary to minimise the designer uncertainty.

Microzonation effects are caused by a combination of unfavourable, often subterranean, features which focus (or disperse) energy as it is transmitted to the surface from the rupture plane. Since such features are particularly site specific, there is at this time no realistic means by which these effects

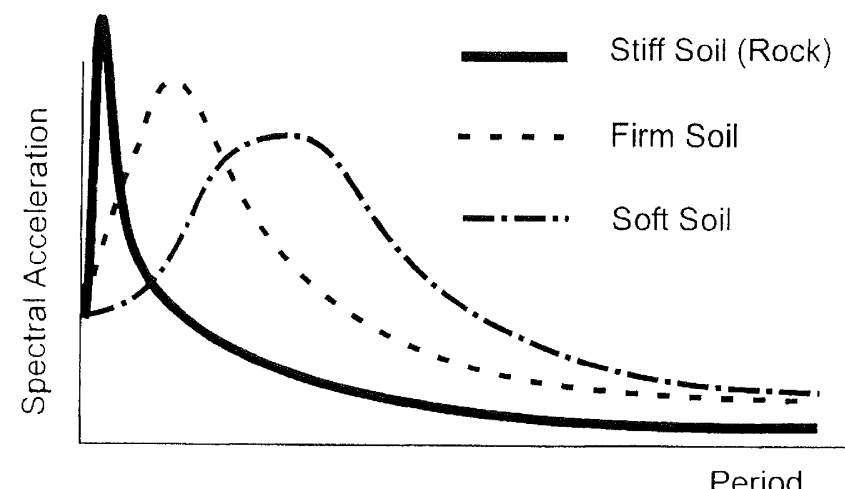

FIGURE 3 Site influence on spectral response 
can be included within design standards. Specific site investigations are required to for the such features to be identified and quantify such effects.

[Anticipated Outcome: Soil modification effects will need to be included. A simple soil related response magnification factor would be preferred, but only if there is confidence that the response spectra is unaffected by the soil effects. Publication of soil specific elastic response would otherwise be acceptable.]

\section{STRUCTURAL RESPONSE TO EARTHQUAKE MOTION}

\{Objective: To prescribe procedures and principles by which the response of a specific structure can be assessed from the elastic site response spectra prescribed above.\}

The dynamic response at a given site has been prescribed within section 3. Rules must now be developed to enable these characteristics to be translated into a design response spectra for a particular building which is to be founded on that site.

The proposed use and occupancy class of the building will affect the mass distribution within the building and often its layout. The selection of the structural form, the materials to be used and the acceptable level of inelastic response all combine to determine the dynamic response of the building.

\subsection{Building/Occupancy Importance (Risk Adjustments)}

\{Objective: To adjust the design response to allow for differing performance expectations associated with the type and importance of end-use\}.

Modern building codes require that collapse be avoided under severe earthquake attack and that functionality (ie before the threshold of damage requiring repair) be maintained when subjected to an intermediate (or serviceability) intensity earthquake. These requirements apply to all buildings, although they may differ from one society to another (and could be adjusted by a National Performance Factor if required). It is common practice however to provide a greater level of security for 'special' buildings. These may be key post-disaster facilities that are required to remain operational following earthquake attack (eg hospitals, emergency management facilities, prisons, etc), or buildings which house national treasures or large crowds (whereby collapse is to be prevented and the contents protected, but subsequent occupancy may not be essential). Heritage buildings require protection against damage to their fabric and provide a special challenge. There is also an increasing trend for businesses to be aware of economic losses associated with post disaster decommissioning of plant and facilities and incorporating preventative measures within the plant design.

The simple approach of scaling the design response spectra according to the building importance is the method adopted within the current New Zealand and Australian earthquake codes [Standards New Zealannd, 1992; Standards Australia, 1993]. Such an approach, while providing greater capacity against collapse and perhaps postponing the onset of damage, does not address the particular performance expectations which may be appropriate for each building. There is an increasing trend overseas to provide base-isolation for essential facilities as a means of actively controlling the level of earthquake excitation which can be reasonably imparted to a building. Where internal damage control is the essential parameter, deformation controi or the provisions of securing high elevation elements against collapse may be more appropriate. There is little doubt that the simple magnification of the design spectra, although a traditionally convenient tool, is due for review.

[Anticipated Outcome: Guidance is required as to how particular performance objectives are best achieved, if necessary by limiting the acceptable design solutions for specific 'special' buildings. While a simple building importance multiplier may be appropriate, a more refined method of matching specific performance expectations with particular control measures or constraints would seem timely.]

\subsection{Structural Form and Inelastic Response}

\{Objective: To establish the inelastic dynamic response of the structure following selection of the structural materials and structural form to be used.\}

The elastic response spectra provides dynamic response characteristics for a particular site. Building damage in rare, major events, is regarded as acceptable provided collapse is avoided. This allows the designer to select an appropriate levels of ductility (inelastic response) for each structure. While this decreases the lateral shear force which is required to be applied for design, it increases the interstorey inelastic displacement. This places greater demands on clearances necessary for secondary components and building contents. The level of damage expected from highly ductile frames is expected to be greater, with the consequence of large post-disaster disruption being expected.

Once the principle of inelastic behaviour has been adopted (usually as an expedient means of reducing construction cost and permitting greater design freedom), a method must be instigated by which the inelastic design spectra for each particular structure can be derived from the site response spectra (as prescribed in section 3 above). The two most common methods are to use a combination of structural ductility and redundancy (the $\mu \sim \mathrm{S}_{\mathrm{p}}$ combination within the New Zealand code and the structural behaviour factor, $q$ of Eurocode 8 ) or alternatively to use a structural response factor, $R_{f}$ (the UBC / Australian approach). Both $q$ and $R_{f}$ are period independent and are therefore inverse scaling factors of the site response spectra. The various inelastic response spectra published within the New Zealand standard introduce period dependency with equal energy concepts being applied to short period structure and equal displacement to long period ones (with a transition between)

In each case, the ability of the structure to sustain levels of inelastic response depends upon the material and the detailing employed. They are material parameters and as such should be prescribed within the seismic provisions of the material design standards together with the detailing requirements which are needed to attain the level of ductility assumed.

(

An important issue is the ability to rationally verify any such reduction factor by test (or other means) to ensure consistency between materials and to allow new systems to be introduced. To facilitate this, there is an increasing trend internationally to derive the inelastic response reduction factor from severa material related variables. In New Zealand the ductility factor, $\mu$, is used to reflect the structural ductility present and the structural performance factor, $S p(=2 / 3)$, is used to adjust the inelastic structural response spectra to reflect the building damage associated with several inelastic excursions. SEAOC have proposed changes to the UBC [Phillips and Hamburger, 
1995] for the 1997 revision which, if adopted, will split the $R$ factor into two parts, namely a ductility reduction component, $R_{d}$, and an overstrength component, $R_{0}$. EC 8 goes further with a basic behaviour factor, $q_{0}$, (ranging from 2.5 to 5 ) and three modification factors associated with the ductility class, $\mathrm{k}_{\mathrm{d}}$ ( 1 to $0.5)$, a regularity function, $\mathrm{k}_{\mathrm{r}}$, (1 or 0.8$)$, and a wall modifier, $\mathrm{k}_{\mathrm{w}}$, which is used to address the prevailing failure mode of wall systems.

[Anticipated Outcome: A quantifiable inelastic response reduction factor will be required. This will be material and structural form dependent and is likely to be composite in character. The structural behaviour factor contained within EC8 offers a good starting point for committee considerations, although the emphasis on energy dissipation may require further consideration.]

\subsection{Seismic Mass}

\{Objective: To prescribe the mass of the building and its contents which should be considered as being present and active during an earthquake attack.\}

The use and occupancy characteristics of a building will usually be used as the basis for determining the live load, Q, which should be considered as present within that structure at various periods during its intended life. The seismic mass assumed present at the time of an earthquake attack is generally the self weight of the structure plus the arbitrary-point-in-time occupancy load, $\mathrm{Q}_{\mathrm{APT}}$ (ie that intensity of live load which has a $5 \%$ probability of being exceeded at any time during that expected life). $\mathrm{Q}_{\mathrm{APT}}$ should be prescribed within the general section of the loading standard. For NZ and Australia this is set at $40 \%$ of the nominal live load specified.

[Anticipated Outcome: The participating seismic mass, and its relative distribution within the structure will need to be prescribed. The intensity of this load may be prescribed within the general loading provisions rather than specifically for earthquake considerations. The reduction factor which relates the probability that mass of this intensity will be applied over all of the contributing area may be specific for earthquake considerations.]

\section{TECHNICAL PROCEDURAL ISSUES (ANALYSIS AND DESIGN LIMITATIONS)}

Clauses within this part focus on the design and analysis procedures which are appropriate for earthquake design within regions of differing seismicity and the attainment of particular earthquake related performance expectations. It sets some limits within which simplified procedures may be applied and beyond which the implicit assumptions made in preparing such alternative methods are no longer valid.

\subsection{Design Application (From 'doing nothing' to capacity procedures and beyond)}

\{Objective: To prescribe a means by which design simplification procedures may be confidently applied while retaining an appropriate level of confidence that building performance expectations will be attained.\}

The necessity to design for earthquake loadings within areas of moderate to high seismicity is seldom challenged. Traditionally, such a consideration has been ignored in areas of low seismicity.
Well designed buildings have been shown to perform satisfactorily in both environments. The challenge in this section is to define appropriate limits which will direct the designer to make provisions for, or to require specific earthquake design to be executed, whilst not demanding that complex earthquake design or construction procedures be imposed unnecessarily.

Such limits should be identified early in the design process so as to avoid unnecessary design effort. The Australian earthquake code sets four levels of design, namely making no specific provisions, imposing simple detailing requirements, using simple equivalent static design and using dynamic design. The boundaries of each level are based upon the building category (which is a function of the peak ground response expected at the site including soil amplification effects and the structural performance expectations) and the inherent resilience (ductility) implicit with the structural system being employed. The implication that dynamic design procedures will result in better building performance are open to question and it may be expected that in future standards the limitations will be directed more to achieving the particular performance expectations which are prescribed.

[Anticipated Outcome: Guidance will be provided which relates the site seismicity to the level of performance expected be included with a view to ensuring that specific earthquake resistant provisions are in place where necessary but can be avoided where the inherent capacity of the building is in excess of that prescribed for the nominated design return period.]

\subsection{Distribution of Earthquake Induced Lateral Loads}

\{Objective: To provide a means whereby the base shear induced by the inertial effect on the seismic mass is rationally and appropriately distributed up the height of each of the vertical lateral load resisting systems and between these systems so as to allow for torsional effects\}.

This section addresses the effects of building irregularity (both vertical and horizontal). Limits are required to specify where the simplifying assumptions are used as the basis of the equivalent static design procedure and where the application of two dimensional design is no longer valid.

Higher mode effects are often caused by abrupt changes in structural stiffness up the height of the structure. Considerable simplifications can be made within the design process if the structure is vertically regular in which case the first mode can be reasonably assumed to dominate. Vertically irregular structures, particularly those of moderate or greater height, must specifically consider higher mode effects (using multi-modal or integrated time history analysis techniques - see section 5.3).

The distribution of total base shear between vertical lateral load resisting system and the influence of torsional twist within the structure is a function of its horizontal regularity. When horizontally regular, accidental eccentricity need only be considered to amplify the lateral loads of the outside lateral load resisting systems. The analysis can be confined to two dimensions in such cases. For horizontally irregular structures, three dimensional analysis or a greater torsional allowance is required. Preparing clear and unambiguous guidelines to access acceptable levels of horizontal regularity is difficult.

[Anticipated Outcome: Regularity, both vertical and horizontal, remains a key issue in accurately predicting the earthquake response of a structure. Guidance will be required as to 
acceptable regularity limits for which simplifying assumptions with respect to the vertical distribution of load apply, and when 3 dimensional analysis is required to address torsion induced by horizontal irregularity.]

\subsection{Methods of Analysis}

\{Objective: To prescribe limits within which various methods of analysis can be used to ascertain the earthquake load effects within the structure and to give guidance as to the various analysis methods should be applied and their results interpreted.\}

\subsubsection{Equivalent Static Method}

The equivalent static method of analysis may only be used to analyse simple regular buildings. The dynamic response of such systems is only used to distribute the total base shear within each frame (usually with an inverse triangulated load pattern), together with an amplification factor to allow for torsional effects. The system is then designed to resist the static loads induced from this distributed load pattern superimposed upon those arising from self weight and long term occupancy loads. Members may be sized and detailed according to the resulting actions, or, if capacity design is required, as a basis for determining the flexural member capacity and the overstrength capacity which is used to ensure the appropriate hierarchy of strength attained.

[Anticipated Outcome: The equivalent static method of design should still be the preferred option for simple structures. The transparent nature of the analysis provides less likelihood of gross errors being introduced. Guidance will be required as to the appropriate sectional properties (stiffness and member end zone allowance), how accidental torsional effects are to be incorporated, and how deformation compatibility can be assured.]

\subsubsection{Multi-Modal Analysis Method}

When more accurate representations of the actual excitation modes of the structure are required, either because of vertical irregularity or for other reasons, the multi-modal method of analysis can be employed. This method determines the actual period and mode shapes of the building which are used, in conjunction with the inelastic response spectra, as the basis for distributing base shear. The contribution from each mode is combined usually using a sum of squares combination technique. The actions derived more realistically represent the building response. Since the contribution of each mode will not occur simultaneously, the means by which they are combined requires careful attention (refer Carr [1994]).

[Anticipated Outcome: Multi-modal analysis procedures will need to be specified. Guidance is required as to methods of combining the resulting modal effects, with particular reference to the time dependant nature of the resulting action envelopes. Methods by which post-elastic response can be assessed would be helpful.]

\subsubsection{Integrated Time History Analysis}

Integrated Time History analysis techniques, although still only being used for major structures, are more widely available with the advent of more powerful, cheaper computing. The process involves developing a computer model of the structure, usually including both the elastically responding characteristics and the post-elastic characteristics of each element. The resulting model, together with the appropriately distributed seismic mass, is subjected to the synthesised ground motion for each time step of the ground motion being considered.

Issues which require to be included in any such analysis are: the dynamic character and scaling effects of the ground motion, the dynamic interaction between interconnected lateral load resisting elements, and the actual inelastic response of the structural components being modelled. Techniques such as these are most commonly used as checking tools once the structural form has been proportioned in accordance with other methods.

[Anticipated Outcome: Integrated time history analysis techniques have become widespread in their use a means of establishing the onset of damage and thus control within a structure. As such guidance will be needed as to how to select appropriate input records and scaling factors to be applied for a specific site and structural form. Guidance is required as to how to interpret and apply the data derived from such analyses. The resulting data should be incorporated into the design process.]

\subsection{Post-elastic Displacement Control}

\{Objective: To ensure displacements are appropriately controlled, that the onset of damage is appropriately deferred and that building and component separation distances are sufficient to prevent collision.\}

The deformation profile of a building, derived from the force based analysis methods discussed in sections 5.3.1 and 5.3.2, provides little useful guidance as to the post-elastic deformations which should be expected during severe earthquake attack. It is usual to merely scale the elastic profile, normally by a factor which relates to the structural ductility assumed. The true post-elastic deformation profile is strongly influenced by the structural form of the building. Framed structures tend to concentrate their post-elastic drift within the lower third of the building (the remainder following an unmodified elastic profile) in contrast with shear wall or cantilever systems in which the amplified elastic deformation approach is more realistic.

Drift control is required under post-elastic conditions to ensure the actions of second-order effects, such as displaced gravity actions (P- $\Delta$ effects), remain small. Accurately assessing such drift is notoriously difficult and the imposed limits are somewhat arbitrary. Typical limits of between 1 and $2 \%$ of interstorey height have been used within international standards.

Separation between buildings and between elements within a building provide a control upon which building clearance and boundary separation are assessed. The potential exists for dynamically unsympathetic responding systems to clash and hammer each other when excited. Impacts of this nature have been observed during recent earthquakes (Mexico 1985) and have resulted in premature structural collapse. Realistic controls on both building and component separation distances will be required within future earthquake codes.

[Anticipated Outcome: Both elastic (serviceability) and postelastic drift limits are needed. The rationale for the imposition of such limits should clearly identified, even if the technical basis for such controls may be somewhat sparse. Guidance will be required to ensure that magnification of the elastic displacement profile is correctly applied to obtain the postelastic displacement profile. ] 


\subsection{Serviceability Displacement Controls}

\{Objective: To provide earthquake induced dynamic actions from which the design of building components and non-structural elements can be designed to attain their required performance.

Damage to non-structural components and elements has been found to be the most common cause of building closure following an earthquake attack. Avoidance of the premature onset of such damage is becoming an increasingly common performance criterion. The implication of this applies both to the elements themselves and to their interaction with, and connection to, the structure and to each other.

The complexity of defining the dynamic response of the structure and the interaction between the structure and the element or supported component becomes much greater and the uncertainty is much more pronounced when the component is elevated within the building. In such cases, the structural response, within both elastic and inelastic range, will be highly influential on the loading pattern applicable to the component, and thus the dynamic response of that element to such loading.

[Anticipated Outcome: A rational method is needed to enable the design of non-structural building components to both serviceability intensity events (after which they should continue to operate) and ultimate limit state events where damage may be acceptable.

\section{HIGHER LEVEL ISSUES}

\{Objective: To identify issues which must be specified to enable consistency of approach across the suite of structural design standards but have application or implications beyond the earthquake part. Such issues would be addressed within either the national building codes or the parent loading standard.

The following issues are fundamental to all structural standards within the suite:

- The proposed objective of the design (protection from hazard, neighbouring buildings, national economic loss, etc.);

- The acceptable design philosophies (Working Stress or Limit State Design);

- Definition of structural and occupancy classes; and

- Load combinations will be required for each design state.

\section{THE CURRENT STATUS OF THE JOINT EARTHQUAKE CODE}

In November 1995, prior to the Pacific Earthquake Engineering Conference in Melbourne, Standards Australia and Standards New Zealand convened a meeting of interested parties to discuss the development of a joint earthquake design standard for New Zealand and Australia. Concern was expressed that too many changes had been imposed on the design profession over recent years and a time of consolidation was required. It was agreed by both Standards organisations that the existing suite of structural codes would remain and be supported for the next 10 years. It was however agreed that the time was right for work to begin on developing a new suite of structural codes, with the earthquake section of the joint loading standard being perhaps one of the more difficult to bring together.

A working party, operating under the name BD6/4, had been established some time previously and was called together in March '96 prior to the Annual NZNSEE conference in New Plymouth. The author was appointed chairman of that working party and, working under the above structure, persuaded a number of participants from both New Zealand and Australia to form working groups to prepare briefing statements and identify the key issues on each of the topic areas discussed above. This process in now well advanced, and will be reported in the Bulletin in the near future. The timetable for executing the work has yet to be finalised, but is expected to extend over the next three years. Funding remains a considerable impediment and there still appears to be no solution in sight.

\section{CONCLUSIONS}

It is quite feasible to prepare a common earthquake design standard for New Zealand and Australia which would be able to accommodate the wide range of seismicity within each country and the level of design refinement present within the respective design communities. Any such standard could be readily adopted by other regions regardless of the level of their seismicity or their stage of social or economic development.

The essential features of most international earthquake engineering design standards have been identified and discussed. Although there are differences in detail, the overall approach is common and with refinements could be readily applied to any future code development.

Earthquake engineering design continues to become more refined and focused on assuring the required structural performance is attained. Several new international initiatives have been identified and should be considered for any future standard development.

\section{REFERENCES}

Carr A.J. 1994. Dynamic Design of Structures. Bulletin NZ National Society for Earthquake Engineering. 27; 129-146

Dowrick D.J. Gibson G, and McCue K. 1995. Seismic Hazard for Australia and New Zealand. Bulletin NZ National Society for Earthquake Engineering, 28; 279-293

Heidebrecht A.C. 1995. Insights and Challenges Associated with Determining Seismic Design Forces in a Loading Code. Bulletin NZ National Society for Earthquake Engineering, 28; 224-247.

International Conference of Building Officials (ICBO). 1992. Uniform Building Code (UBC), Whittier, California.

Phillips R.J. \& Hamburger R.O. 1995. SEAOC Proposed Major Seismic Changes in Response to Northridge. International Conference of Building Officials, Building Standards, July Aug:13-22

Priestley, M.J. Nigel 1993. Myths and Fallacies in Earthquake Engineering - Conflicts between Design and Reality. Bulletin NZ National Society for Earthquake Engineering, 26; 329335 . 
Standards Australia, 1993. AS 1170.4 Minimum Design Loads on Structures Part 4 - Earthquake Loads, NSW 2140, Australia.
Standards New Zealand, 1992. NZS 4203:1992 Code of Practice for General Structural Design and Design Loadings for Buildings, Wellington, New Zealand.

APPENDIX A

Comparison of issues covered in several international earthquake standards

\begin{tabular}{|c|c|c|c|c|c|c|}
\hline & ISSUES & AUS $^{\prime}$ & $\mathrm{NZ}^{2}$ & $\mathrm{EC}^{3}$ & $\mathrm{UBC}^{4}$ & $\mathrm{ISO}^{5}$ \\
\hline & SITE PARAMETERS & & & & & \\
\hline 4.1 & Elatstic Response Spectra & $\begin{array}{c}\text { normalised } \\
\left(1.25 \mathrm{~S} / \mathrm{T}^{2 / 3}\right)< \\
2.5 \\
\text { eqns and graphs }\end{array}$ & $\begin{array}{l}3 \text { (soil category) } \\
2 \text { segments } \\
\text { graphs \& tables }\end{array}$ & $\begin{array}{l}\text { parametric } \\
4 \text { segments } \\
\text { equs \& tables }\end{array}$ & $\begin{array}{c}\text { parametric } \\
3 \text { segments } \\
\text { graphs \& tables }\end{array}$ & $\begin{array}{c}\text { parametric } \\
\rho_{0}\left(T_{c} / T\right)^{1}<\rho_{0} \\
\text { graphs \& tables }\end{array}$ \\
\hline 4.2 & $\begin{array}{c}\text { Seismic Zonation map return } \\
\text { period }\end{array}$ & $10 \%$ in 50 years & $10 \%$ In 50 years & 475 yrs & 475 yrs & not specified \\
\hline \multirow[t]{2}{*}{4.3} & Soil Classification & 5 classes & 3 classes & 3 classes & 5 classes & not specified \\
\hline & PROCEDURES & & & & & \\
\hline 5.1 & Important factor & $1-1.25$ & $1-1.3$ & not specified & $1-1.25$ & not specified \\
\hline 5.2 & $\begin{array}{l}\text { Inelastic Structural Response } \\
\text { (Seismic resisting system) }\end{array}$ & $\begin{array}{c}\mathrm{R}_{\mathrm{f}} \\
(1.5-8.0)\end{array}$ & $\begin{array}{c}\mu \text { and } S_{1} \\
(1.25-6.0,0.67)\end{array}$ & $\begin{array}{c}q=q_{0} k_{\mathrm{d}} \mathrm{k}_{\mathrm{r}} \mathrm{k}_{\mathrm{w}} \\
\mathrm{q}_{0}=2-5 \\
\mathrm{k}_{\mathrm{d}}=0.5-1 \\
\mathrm{k}_{\mathrm{r}}=0.8-1 \\
\mathrm{k}_{\mathrm{w}}=0.4-1\end{array}$ & $\begin{array}{c}\mathrm{R}=\mathrm{R}_{\mathrm{d}} \mathrm{R}_{0} \\
\mathrm{R}_{\mathrm{d}}=1.2-3.4 \\
\mathrm{R}_{0}=1.8-2.5\end{array}$ & $\begin{array}{c}\delta \\
1 / 5-1 / 3 \text { ductile } \\
1 / 2-1 \text { non- } \\
\text { ductile }\end{array}$ \\
\hline \multirow[t]{2}{*}{5.3} & Seismic mass & $\mathrm{G}+1 / \mathrm{cQ}$ & $\mathrm{G}+\psi \mu \mathrm{Q}$ & $\mathrm{G}+(\rho) / 21 \mathrm{Q}$ & $\mathrm{G}+\times \mathrm{Q}$ & \\
\hline & DESIGN APPLICATIONS & & & & & \\
\hline 6.1 & $\begin{array}{l}\text { Levels of design } \\
\text { Do nothing } \\
\text { details only } \\
\text { conventional design } \\
\text { capacity design } \\
\text { displacement design }\end{array}$ & $\begin{array}{c}\text { fn(aS, bld. type }) \\
\text { fn(aS, bld. type }) \\
\text { fn(aS, bld. type }) \\
\text { not required } \\
\text { not covered } \\
\end{array}$ & $\begin{array}{c}\text { not allowed } \\
\text { not allowed } \\
\mu \text { related } \\
\mu \text { related } \\
?\end{array}$ & $\begin{array}{c}a<0.04 g \\
a<0.1 \mathrm{~g} \\
a>0.1 \mathrm{~g} \\
? \\
? \\
\end{array}$ & $\begin{array}{c}\text { zone } 0 \\
\text { if wind control } \\
\text { required } \\
\text { not required } \\
?\end{array}$ & not specified \\
\hline 6.2 & Structural regularity criteria & Yes & Yes & Yes & Yes & \\
\hline 6.3 & $\begin{array}{c}\text { Methods of analysis } \\
\text { Equivalent static } \\
\text { Modal } \\
\text { Time history }\end{array}$ & $\begin{array}{c}\text { Cat } \mathrm{B} \text {, irregular } \\
\text { Cat } \mathrm{C} \text { or above, } \\
\text { regular } \\
\text { Cat } \mathrm{D} \text { or above, } \\
\text { irregular } \\
\text { optional }\end{array}$ & $\begin{array}{c}\mathrm{H}<15 \mathrm{~m} \\
\text { regular } \mathrm{T}<2.0 \mathrm{sec} \\
\text { irregular } \mathrm{T}<0.45 \mathrm{~s} \\
\text { outside equivalent } \\
\text { static limits } \\
\text { outside equivalent } \\
\text { static limits }\end{array}$ & $\begin{array}{c}\text { (i) regular } \\
\text { (ii) limited class } \\
\text { with } \mathrm{T}<2 \\
\text { outside } \\
\text { equivalent static } \\
\text { limits } \\
\text { outside } \\
\text { equivalent static } \\
\text { limits } \\
\end{array}$ & & \\
\hline 6.4 & $\begin{array}{l}\text { Post-elastic Displacement } \\
\text { Control }\end{array}$ & $\Delta_{c}(3 R / 8)$ & $\mu \Lambda_{e}$ & $q_{11} \Delta_{e} \gamma_{1}$ & $0.7 \mathrm{R}_{\mathrm{d}} \mathrm{R}_{0}$ & \\
\hline 6.5 & $\begin{array}{l}\text { Serviceability control } \\
\qquad-\delta\end{array}$ & $\begin{array}{l}m>0.1 \\
0.015 \mathrm{~h}\end{array}$ & $\begin{array}{c}\text { not required for } \\
\mathrm{T}<0.45 \mathrm{~s} \\
\mathrm{H}<15 \mathrm{~m} \text { and } \\
\mathrm{T}<0.8 \mathrm{~s} \\
\mu<1.5 \\
0.02 \mathrm{~h} \text { for } \mathrm{H}<15 \mathrm{~m} \\
0.015 \mathrm{~h} \text { for } \\
\mathrm{H}<30 \mathrm{~m}\end{array}$ & $\begin{array}{c}0.0 \mathrm{ish} \text { to } \\
0.008 \mathrm{~h}\end{array}$ & $\begin{array}{c}\mathrm{m}>0.1 \\
\\
0.025 \mathrm{~h} \text { for } \\
\mathrm{T}<0.7 \mathrm{~s} \\
0.020 \mathrm{~h} \text { for } \\
\mathrm{T}>0.7 \mathrm{~s} \\
\end{array}$ & \\
\hline 7 & Design methods & WSD \& LSD & LSD & LSD & WSD \& LSD & LSD \\
\hline
\end{tabular}

${ }^{1}$ Australian Standard AS1170.4-1993. Earthquake Loads

${ }^{2}$ New Zealand Standard NZS 4203:1992 Part 4 : Earthquake Provisions

${ }^{3}$ European Prestandard EuroCode 8 - Design Provisions for earthquake resistance of structures

${ }^{4}$ Uniform Building Code-SEAOC - including the latest changes as approved by ICBO

${ }^{5}$ International Standards Organisation ISO-3010 Basis for design of Structures- Seismic Actions 